\title{
Popüler Fizik Kavramları İçeren Görsel Ders Materyali Geliştirme Çalışması*
}

\section{Nasip DEMİRUŞ**, Salih GÜLEN***}

Öz: Popüler fizik kavramları ile ilgili web sitesi, kütüphane, aktüel ders notları, makaleler ve belgesel filmlerden gerekli envanter toplanarak görsel bir eğitim materyali hazırlanmıştır. Araştırmanın amacı sanal ve görsel ders materyali geliştirmektir. Araştırmada geliştirilen materyalin eğitime etkisini ölçebilmek için ön çalışma yapılmış ve olumlu sonuçlar alınmıştır. Araştırmada doküman incelemesi yapılmıştır. Toplanan tüm veriler, bilimsel yöntemler ve materyal geliştirme kriterlerine göre değerlendirilmiştir. Araştırmada 1173 görsel, işitsel ile 24 görsel ve tanımsal toplam 1197 kavram hazırlanmıştır. Toplanan tüm kavramlar sanal programlar ile internet entegreli olarak DVD'de toplanmış ve http://www.biyolojiegitim.yyu.edu.tr/kf/sg/sg.html adresine konumlandırılmıştır.

Araştırmanın benzer çalışmalara yardımcı olabilmesi için kullanılan sanal araçlar, izlenen yollar, yöntemler ve yapılan işlemin her aşaması yöntem kısmında anlatılmıştır. Araştırmanın kazanımları, eğitime katkısı ve elde edilen yargılar sonuç ve öneriler kısmında sunulmuştur.

Anahtar Kavramlar: Eğitim materyali, Popüler Fizik Kavramları, Kavram

\footnotetext{
*Bu Çalışma, Popüler Fizik Kavramları İçeren Görsel Ders Materyali Geliştirme Çalışması Yüksek Lisans Tezinin bir bölümüdür.

**Prof. Dr. Ortaöğretim Fen ve Matematik A.B.D./Biyoloji Eğitimi/ nasip@hotmail.com/

*** Dr. Öğretmen/Kuşkayası Ortaokulu/19 Mayıs-Samsun/ sgnova@windowslive.com
} 


\title{
Development of Visual Course Material Containing Popular Physics Concepts
}

\begin{abstract}
The visual instruction material related to popular physics concepts was developed through collecting inventory materials from web sites, library, course text, articles and documentary films. Purpose of the research is developed virtual and visual course material. A preliminary work has been done to measure the impact of developed materials in the study and positive results have been obtained. Document review has been done in the research. All data collected was evaluated according to scientific method and criteria for materials development. In total 1197 concepts -1173 visual and auditory and 24 visual and definitionalwere created. All concepts were collected via visual programs on DVD with the internet linked and has been placed on this site http://www.biyolojiegitim.yyu.edu.tr/kf/sg/sg.html Virtual instruments used, tracked trails, each stage of the process and methods were described in method section to help for similar studies. The gains of the research, education contribution and judgments obtained were presented in results and suggestions parts.
\end{abstract}

Keywords: Visual Materials, Popular Physics Concepts, Concept 


\section{Giriş}

Soyut ve ulaşılması zor olan kavramların eğitiminde görsel-işitsel ve sanal kavramların kullanımı son derece önemlidir (Gülen ve Demirkuş, 2014b). Kavramlar düşüncenin birimleridir. Bilgilerin yapı taşlarıdır. Kavramlar doğa ve ötesindeki; olgu, olay yaratık ve herhangi bir şeyi anlam bütünlüğü açısından temsil eden kodlanışın ifade şeklidir (Demirkuş, 2017a).

Kavramlar sanal ve soyut olma özelliklerinin yanı sıra ulaşamama gibi bir özellikte de bulunabilirler. Günlük hayatımızda da sürekli kullandığımız popüler fizik kavramları insan elinin değimi veya ulaşımının oldukça zor olduğu kavramlardır. Büyük Patlama, Parçacık Fiziği, Uzay, Hubble Uzay Teleskopu, asteroitler, yıldızlar, Quasar, bleysar, kara delik ve Dünya'mız veya Güneş Sistemi gibi kavramlar ulaşamadığımız ya da şeklen bir yere oturtamadığımız binlerce kavramlardan sadece bazılarıdır. Bu kavramlar toplumda popüler fizik kavramları olarak bilinir. Bu kavramların öğretilmesinde ve bireyin bu alanda yapacağı eğitimde kullanılan materyal önem arz etmektedir (Aydemir Özyurt, 2016). Kavramların görsel ve işitsel olarak sunulabilmesi için hazırlanan materyaller kavram eğitiminde kolaylık sağlamaktadır (Gülen, 2010; Gülen ve Demirkuş, 2014b).

Kavramların görsel-işitsel olarak hazırlanması Latince 'görmek' fiiliyle aynı kökten gelen ve "görü" ya da "görünür olma" gibi anlamları olan videoyu anımsatmaktadır (Şahin, 2016). Sesi, hareketi ve görüntüyü bir arada sunan televizyonda, webde veya mobil cihazlarda yayımlanan video son derece değişik amaçlarla çekilen ve paylaşılan popüler bir ilgi alanına dönüşmüştür. Reklam, film, müzik, tanıtım ve eğlenceye kadar yaşamın her 
alanında görülen video uygulamalarının etkin olarak kullanıldığı ortamlardan biri de eğitimdir (Ata ve Atik, 2016; Babacan, 2015).

Eğitim öğretimde görsel materyalin önemi ile öğrenmede görme duyusunun önemi benzerlik göstermektedir. Çocukların ilk yaşlarından itibaren televizyon programlarındaki taklitlerinden dolayı konuşmada ve kavram öğrenmede daha hızlandıkları tespit edilmiştir (Çakır, 2014). Söz konusu etkiden dolayı günümüz eğitim sisteminde de gelişen ve ilerleyen teknolojinin imkânlarından faydalanıp, bireyin kavram eğitiminde önemli bir etkeni olan görsel ve işitsel materyallerin hazırlanması gerekmektedir (Gülen ve Demirkuş, 2014a; 2014b).

Kavramları vurgulayan, anlatan veya resmeden görüntüleri parçalayıp eğitsel amaçlara uygun bir yöntemle yeniden bir araya getirebilme olanağı videoyu insan algısını eğiten görüntüler haline getirebilmektedir. Bu tarz hazırlanan materyaller internet ve mobil uygulamalar sayesinde zaman ve mekândan bağımsız olarak her zaman ve her yerde ulaşılabilecek bir konumdadır. Özellikle başlatma, durdurma ve saklama hatta tekrarlama gibi eylemler bu materyallerin vazgeçilmez özelliğini pekiştirmektedir. Ayrıca öğrenmeyi zenginleştirme becerisi yanında bilginin paylaşımındaki denge ve tutarlılığıyla kalitesini artırmaktadır (Demirkuş, 2017b; Halls, 2012). Görsel ve işitsel materyalin bu denli önemli olabilmesini sağlayan şüphesiz gelişimini hızla ilerleten teknolojidir. Özellikle bilişim ve iletişim teknolojileri bilgisayar, cep telefonu ve internetin gelişimi günümüzde görsel ve işitsel materyallerin önemini artırmaktadır (Akalın, 2012). Nitekim Milli Eğitim Bakanlığı hem FATİH projesi ile hem de değişimini hedeflediği taslak programda materyal geliştirme ve kullanımını önemi vurgulanmıştır (MEB, 2013: 2017).

Öğretimde materyal, soyut kavramların somutlaştırılmasında ve ulaşılması zor kavramların modellenmesinde kullanılan araçlardır (Gürbüz, 2006). Bu materyallerin 
seçiminde bazı kriterler göz önünde bulundurulur. Materyal seçiminde ilk adım öğretilecek konu için gerekli öğrenci performansını, bu bağlamda hedef kitleyi ve bunların karakteristikleri ile öğrenme tiplerini belirlemektir. Öncelikle materyal kullanılacak kitlenin büyüklüğü ve öğrenme tipleri belirlenmeli ardından metot seçilmelidir. Metot seçiminde bu özelliklerin yanı sıra para, zaman gibi imkânlarla öğrenci özellikleri de dikkate alınmalıdır. Uygun metot seçiminden sonra öğretmen becerileri ve imkânlar da bu işleme katılarak son aşama olan materyal seçimine geçilmelidir (Bayram, 2006).

Öğretimde hazırlanacak olan materyalin bazı özellikleri olmalıdır. Bu özellikler aşağıdaki gibi belirlenebilir.

1. Basit, sade ve anlaşılır olmalı,

2. Ders programlarını destekleyici biçimde dersin hedef ve kazanımlarına uygun seçilmeli,

3. Dersin konusunu oluşturan bütün bilgilerle değil, önemli ve özet bilgilerle donatılmalı,

4. Kullanılacak görsel özellikler materyalin önemli noktalarını vurgulamak amaciyla kullanılmalı, aşırı kullanımdan kaçınılmalı,

5. Kullanılan yazılı metinler, görsel-işitsel öğeler, öğrencinin pedagojik özelliklerine uygun olmalı ve öğrencinin gerçek hayatıyla tutarlılık göstermeli,

6. Öğrenciye alıştırma ve uygulama imkânı sağlamalı,

7. Mümkün olduğunca gerçek hayatı yansıtmalı,

8. Öğretim materyali her öğrencinin kullanımına ve erişimine açık olmalıdır.

9. Öğrencilerin kullanabileceği düzeyde basit olmalı,

10. Tekrar kullanılacak materyaller dayanıklı hazırlanmalı, bir defalık kullanımlarda zarar görmemeli,

11. Gerektiği takdirde, kolaylıkla geliştirilebilir ve güncelleştirilebilir olmalı, 
12. Hazırlanmasında yakın çevreden her türlü yardım için çaba harcanmalı ve yardım alınmal1,

13. Materyalin hazırlama ve kullanım kılavuzları oluşturulmalı, belirtilen bu özelliklerin dışında materyal hazırlamada uyulması gereken ilkelerde bulunmaktadır (Seferoğlu, 2006; Yelken, 2009). Söz konusu ilkeler materyal başlığg altında sunulmuştur.

Araştırmanın Önemi: Görsel, işitsel ve ilişkisel olarak; popüler fizik kavramlarının özgünlüklerine ve ortak özelliklerine dayalı tanımlarının doğadaki karşılıklarına dayalı olarak bu kavramların, isimlerin ilişkilerini anlamsal bir bütünlük içerisindeki kâinat kavram çözmecesinin (pazılının) parçaları niteliğinde ortaya koymak büyük önem taşımaktadır. Var olan eğitim sistemimizde; popüler fizik ile ilgili kavramların çoğu yabancı dilden tercüme edilmiştir. Ya sadece yazılı tanımları veya ilave olarak bazı görüntü ve resimlerle izah edilmeye çalışılmıştır. Ders ve eğitim kitaplarının sonunda sadece yazılı tanımları şeklinde yer almaktadır. Ya da sadece ders kitapları sonunda isimleri ve bulundukları sayfa yerleri şeklinde yer almaktadır. Bu durum eğitimde büyük bir eksiklik olarak göze çarpmaktadır (Özoğlu ve Misıroğlu, 2015).

Kavramlar öğretilir ve öğrenilirken sadece yazımsal tanımları ya da sadece görsel, işitsel tanımlarını kopuk ve ayrı sunmak kavramların öğrenilmesini kalıcı hale getirmede eksik kalabilir. Bu nedenle kavramların; yazımsal, görsel ve işitsel bir ilişki bütünlüğü içerisinde bir arada verilmesi, öğrencilerde daha kalıcı öğrenmeyi güçlendirir (Gülen ve Demirkuş, 2014b). Araştırmadaki ve hazırlanan DVD'deki bilgilerin internete bütünleşik olarak sürekli güncellenebilir nitelikte hazırlanması eğitimin geleceği açısından çok büyük önem taşır. Öğretimde kavramların doğru anlaşılması, öğrenilmesi, uygulanması ve kullanılması için; veri toplama, değerlendirme ve işlemesine yönelik yöntem geliştirilmelidir. 
Toplanan verileri daha ekonomik olan sanal ortamda kullanabilir hale getirmek için; izlenen yöntemler ve tercih edilen sanal-nesnel araçların kullanım şekilleri bakımından gelecekteki benzer çalışmalara örnek oluşturması önemlidir. Gelecekte yapılabilecek benzeri öğretim, öğrenim ve eğitim çalışmaları için veri kaynağı oluşturabilmek önemlidir. Öğretim, öğrenim ve eğitim sürecinde öğrenci zihnini; sürekli zinde ve alıcı bir konumda tutmak önemlidir. Popüler fizik kavramlarının eksik, yanlış veya liyakatsiz konumlarını gerçekçi bir şekilde düzenlemek; öğretim, öğrenim ve eğitim açısından büyük önem taşımaktadır. Günlük hayatta sıkça kullanılan popüler fizik kavramlarının zihinsel olarak şematize edilmesi ve özümsenmesi kavramın öğrenilmesinde görsel materyalin etkisi olacağı düşünülmektedir.

Araştırmanın Amacı: Araştırmanın başlıca amacı; popüler fizik kavramlarının ve kavram kümelerinin zihne doğru yerleşmesi ve doğru bir şekilde öğrenilmesi için, eğitim camiasına materyal hazırlamaktır. Araştırma konusu ile ilgili kavramların görsel-işitsel (kavram ve kavram kümesi filmi), yazımsal (kavram tanımı ve kavram filmi özeti), zamansal (filmin süresi) ve konumsal (kavram kümesi) tanımlarının bir arada veren bir materyal geliştirebilmektir. Ders materyali seçimine ve hazırlanmasına örnek teşkil edebilmesi amaçlanmıştır. Popüler fizik kavramlarının internet üzerinden herkesin yararlanabileceği bir eğitim sitesinde hizmete sunulmasını sağlamaktır.

\section{Yöntem}

Çalışmada nitel veri toplama tekniklerinden doküman incelemesi yapılmıştır. Nitel araştırmalarda verilerin toplanmasında kullanılabilecek dört temel yöntemlerden biri olan doküman incelemesi verilerin objektif bir şekilde amaca uygun olarak analiz edilmesidir (Çokluk, Yılmaz ve Oğuz, 2011). Belgesel ve makale gibi bilimsel içeriklerden elde edilen görsel-işitsel ve yazımsal veriler aşağıda belirtilen materyal geliştirme ilkeleri yöntemine bağlı kalarak öğretim materyali haline getirilmiştir. 


\section{Materyal}

Araştırmanın amacına ulaşmada bağlı kalınan materyal geliştirme ilkeleri aşağıda sırası ile belirlenmiştir.

1. Anlamlılık ilkesi: Bu ilkeye bağlı kalarak yapılan çalışmanın anlamlı bir bütünlük sergilemesi için kullanılan tanımlar ve yazıların olumlu, düzgün cümleler olmasına dikkat edilmiştir. Bu amaçla Yüzüncü Y1l Üniversite Ferit Melen Kütüphanesi toplu veri taramadan, internetteki arama motorlarından (google, yahoo, ... ) makalelerden ve belgesel kanallarından elde edilen veriler bu ilkeye bağlı kalarak düzenlemiştir.

2. Bilinenden başlama ilkesi: Materyali hazırlarken seçilen kavramlar basitten karmaşığa, bilinenden bilinmeyene ve somuttan soyuta doğru gidilecek şekilde düzenlenmiştir. $\mathrm{Bu}$ amaçla seçilen kavramlar alfabetik sıraya göre sıralanmış, her harfe (W, Q, X dâhil) göre sınıflandırılmış ve internet entegreli olarak link atılmıştır. Ayrıca DVD si hazırlanmıştır.

3. Çok örnek ilkesi: Bir kavramın genişliğini göstermek için çok sayıda örnek sunmak gerekir. $\mathrm{Bu}$ amaçla araştırmanın envanterinde bulunan kaynaklardan seçilen kavramların sayısı birden fazla tutulmuştur. Ayrıca bir kavramı farklı şekillerde anlatan kavram filmlere yer verilmiştir. Bazı kavramlar ise hem .pdf hem de .swf olarak hazırlanmıştır.

4. Görelik ilkesi: Özellikler birbirine göre algılanır. Resim ve şekilleri herkes başka şekilde algılamamalı, birbirinden ayırt edebilmelidir. Bu amaçla materyali kullanacak her öğrencinin aynı şeyi kavrayabilmesi için kavramların yazı puntosu, arka fonu, ses düzeyi, ekranı kaplama oranı eşit tutulmuştur.

5. Seçicilik ilkesi: Öğretim materyalindeki önemli elemanları dikkati en çok çekecek şekilde yerleştirmek gerekir. Bu amaçla ana unsuru ortaya çıkartacak olan renkler kullanılmıştır. Kavramın tanımları kavram filmin altına, öğrencinin okuyabileceği şekilde yerleştirilmiştir. Yazının okunabilmesi için arka fon üzerinde rahat gözüken renkle boyanmıştır. 
6. Tamamlama ilkesi: Bir olayın ya da eşyanın tümüne ilişkin çizgileri vermek yerine bir kısmını vermek yeterli olabilir. Bu amaçla ana filmden kesilen her kavram öğrencinin ana film hakkında yorum yapabilmesini sağlayacak şekilde seçilmiştir. Her kavramın tanımının yanında ana filme ve hatta ana filmden kesilen diğer kavramlara ulaşabileceği "Kavram Kümesi” adında bir link bırakılmıştır. Kavram kümesi; bir filmden kesilen tüm kavramların internet entegreli halde bir arada gösterildiği .pdf uzantılı kümedir.

7. Fonun Anlamlılı̆̆ı ilkesi: Şekil ya da yazıya anlam katacak bir fon olmalıdır. Materyal hazırlanırken her kavramın tanımı yeşil zeytin rengi üzerine okunabilen sarı renk kullanılmıştır. Kavramın ismi açık mavi ve kavram kümesi linki ise mavi renk kullanılarak belirtilmiştir. Ayrıca kavram kümesi açık yeşil renk üzerinde açık turuncu arka planlı kırmızı renkte kavram isimleri yazılmıştır. $\mathrm{Bu}$ renk uyumu materyal geliştirmede kullanılan renk cetveline göre yapılmıştır.

\section{http://www.biyolojiegitim.yyu.edu.tr/ders/renk/renkcetveli.html\#renk}

8. Kapalılık ilkesi: Şekiller belirgin olmalı, açık ve yarım bırakılmamalıdır. Özellikle iki boyutlu figürler için şekil tam yapılmalıdır. .pdf uzantılı kavramlar seçilirken sahip oldukları resimleri bu özelliğe uygun olmasına dikkat edilmiştir. Silik olan ya da amaca hizmet etmeyen resimler kullanılmamıştır.

9. Birleştiricilik ilkesi: Birbiriyle benzerliği ve yakınlığı olan nesne ve olaylar ilişkili olarak algılanır ve daha iyi hatırlanır. Bu amaçla kavramlardan aynı veya benzer konuları anlatanları bir birine yakın tutulmuştur. Ya da alfabetik listelemede ard arda düşebilmeleri için uygun şekilde isimlendirilmiştir.

10. Algıda değişmezlik: Öğrencinin önceden bildiği nesneler çok basit çizgilerle verilebilir. $\mathrm{Bu}$ amaçla öğrencilerin çok iyi bilebileceği bir kavramı anlaşılması zor olan bir kavram film 
veya .pdf uzantılı kavramlar kullanılmamıştır. Daha çok toplumun kolay anlayabileceği kavramlar seçilmiştir. Ayrıca tanımları öğrenci seviyelerine uygun olarak yazılmıştır.

11. Derinlik ilkesi: Doğadaki varlıklar bize yakın ise gerçek ölçüleri ve renkleriyle görünürler. Aynı varlıklar uzaklaştıkça, küçülüyor ve renkleri de soluyor hissini verir. Kavramlar belirlenirken bu ilkeye uymayan filmlerden kavram kesilmemiştir.

12. Yenilik ilkesi: Dikkat, özellikle geçirile gelen ve yakın geçmişteki yaşantılara zıt olan durumlara ve yeniye çekilir. Hazırlanan materyalde özellikle bu konuya dikkat edilmiştir. Yapılan internet araştırmasında veya çevre araştırmasında bu tarzda herhangi materyalin olmadığı görülmüştür. Özellikle kavramları filmle öğretme ve öğrenme, hazırlanan kavram kümesinin yeni ve özgün olduğu görülmüştür.

13. Basitlik ilkesi: Dikkati çekmesi ve üzerinde tutması için, bir görsel aracın elemanları karmaşık değil basit olmalıdır. Bu amaçla genel basitliği seçmek için kavramlar alfabetik sıralamaya konulmuştur. Her harfe uygun olarak sınıflama yapılmış, linkler atılmış ve bu linkler tek linkte birleştirilmiştir. Bunlar DVD’ de birleştirilmiştir. DVD’ nin her bilgisayarda açılabilmesi için DVD' ye otomatik çalıştırıcı atılmıştır. Ayrıca gerekli programlar ve uyarılar eklenmiştir.

14. Hedef-davranış ilkesi: Kullanılacak araç, kazanılması öngörülen hedef davranışı oluşturabilecek nitelikte olmalıdır. Bu ilke çerçevesinde hazırlanan kavramlar yazılı, görsel, görsel-işitsel bazı kavram gruplarının verimlilik oranını denemek için Milli Eğitim Bakanlığına bağlı bir okulda uygulanmıştır. Buradan elde edilen istatistikî veriler değerlendirilmiş ve elde edilen sonuçlar, görsel-işitsel materyal kullanılarak yapılan eğitimin, daha etkili olduğunu kanıtlanmıştır (Gülen ve Demirkuş, 2014a; 2014b).

15. Öğrenciye uygunluk: Kullanılacak araç, öğrencilerin özelliklerine (yaş, zekâ ve geçmiş yaşantıların düzenine) uygun olmalıdır. Hazırlanan materyal ilköğretim, ortaöğretim, lise ve 
lisans öğrencilerinin kullanabileceği kavramlarla donatılmıştır. Her düzeydeki öğrencilerin materyali kullanabilmesi için onların seviyelerine uygun olacak kavramlar seçilmeye çalışılmıştır (Demirkuş, 2017b).

Yukarıda belirtilen ilkeler ışı̆̆ında hazırlanan materyalde izlenen teknik aşamalar aşağıda belirtilmiştir.

1. Belgesel filmler en az ikişer kez izlenip özetleri çıkarılmış, hangi kavram ve kavram kümelerinin oluşturulacağı not edilmiştir.

2. Özetle birlikte filmin ayrıntılarına yönelik sorular çıkartılmıştır. Seçilen bu filmlerin özetleri ve soruları html uzantılı olarak internet üzerinde yayımlanmak üzere hazırlanmıştır.

3. Tespit edilen kavramların tanımları yazılmıştır. Kavramların aslına ulaşabilmek için her kavram ismine link atılmıştır.

4. Her bir kavram film için ayrı bir klasör açılmış ana film ve oluşturulan kavramlar bu klasör içine konulmuştur.

5. İzlenen belgesel filmlerin kavramlara ait bölümleri tespit edilmiş ve Ulead Media Studio 7 Video Editör (Demo) programı yardımıyla kesilip ses ve görüntü düzenlemeleri yapılmıştır.

6. Kesilmiş olan bu filmler Flash Encoder ile sıkıştırılarak .mpeg formatından .flv uzantısına dönüştürülmüştür.

7. Her bir kavram filmi Macromedia Flash 8'le düzenlenerek ilgili kavramın tanımı, özellikleri, özgünlükleri, süresi eğitsel fon ve yazı renklerinde film çerçevesinin altına oturtularak .swf video dosyaları hazırlanmıştır.

8. Seçilen bu filmlerin özetleri .html olarak internet üzerinde yayımlanmak üzere hazırlanmış ve genel fillm sayfası üzerine Filmin Özeti adıyla link atılmıştır. 
9. Çok sayıda (en az 4 kavram) kavramlardan oluşan her filmin kavram gruplarının kavram ilişkilendirme araciyla (ConceptDraw Office Pro, ConceptDraw MINDMAP (Demo)) ilişkisel kavram öbeği veya kümesi sayfaları hazırlanmıştır.

10. Flash programıla hazırlanan bu kavram filmleri her birisi birer klasör içine kodlanarak Macromedia Dreamveaver 8 web editörü ile harf sırasına göre düzenlenerek, ilgili linkler atılarak internet üzerinden yayınlanmak üzere web sayfaları oluşturulmuştur.

11. Popüler fizik kavramları ile ilgili 1173 adet .swf ve 24 adet .pdf envanter Yüzüncü Y11 Üniversitesi Biyoloji Eğitimi web sayfasına atılmıştır.

12. Her bilimsel filmden kesilen kavramların .pdf uzantılı kavram kümesi sayfası hazırlanmıştır. Bu kavram kümesi sayfasına ilgili filmin ismine ve kavramlara ilgili filmlerinin linkleri atılmıştır. Bu kümelerde yer alan her kavramdan ilgili kavram filmine ve tanımına ulaşılacak şekilde linkler atılmıştır.

13. Araştırma başlığındaki kavramlara dayalı olarak, Yüzüncü Yı1 Üniversitesi Ferit Melen Kütüphanesi toplu veri tarama sayfasından, internet arama motorlarından veri arama kurallarına uygun olarak internette araştırma ile ilgili web sayfalarına ve bilimsel çalışmalara ulaşılarak özetleri alınmış ve edinilen bilgiler ilişkisel olarak araştırmadaki gerekli yerlere konumlandırılmıştır.

14. İnternette indirilen 540 makale araştırma başlığındaki konulara uygun olarak disipline edilerek araştırma endeksli olarak biyoloji web sayfasında yayına konulmuştur. http://www.biyolojiegitim.yyu.edu.tr/makale.html

15. Hazırlanan web sayfası linkleri ve 1173 kavramın tanımları içeren filmleri; Biyoloji Anabilim Dalı web sayfasına aktarılmak üzere; Adobe Macromedia web ürünleri (Adobe Acrobat Writer, Flash, Flash Encoder, Dreamweaver web editörü ve Fireworks grafik aracı) kullanılmıştır. Aynı web materyalleri (video filmler ve görüntüler) kavram tanımlarıyla 
eşleştirilerek; Popüler Fizik Kavramları İnternet Entegreli Tanım Video-Görüntü DVD’si hazırlanmıştır.

http://www.biyolojiegitim.yyu.edu.tr/kf/sg/sg.html

Veri Toplama Araçları: Hazırlanan materyalin içerdiği tüm kavramların hazırlanmasında, Discovery Channel, National Geographical Channel, History Channel, Realty TV, BBC Premium... vb kanallardan kaydedilen bilimsel belgeseller kullanılmıştır. Ayrıca Bilim ve Teknik, PCnet ve Chip dergilerinin ücretsiz sunduğu DVD eklerindeki görüntü ve videolarından yararlanmıştır.

Kavram filmlerin hazırlanmasında, Adobe Macromedia Dreamweaver web Editörü, Ulead Media Video Editörü, Flash ve Flash Encoder, ConceptDraw MINDMAP gibi sanal araçlar kullanılmıştır.

Verilerin Analizi: Araştırmada elde edilen veriler betimsel ve içerik yönüyle analiz edilmiştir. Analizler sonucunda alan uzmanı iki fen bilimleri öğretmeni ile bir öğretim üyesinin beraber incelemesiyle kavramlar belirlenmiştir. Belirlenen her bir kavramın hazırlanmasında çeşitli sanal araçlar kullanılmış ve bu kavramlar pilot uygulamaya konulmuştur. Uygulama sonucunda gerekli düzenlemeler yapılarak kavramların son hali elde edilmiştir. Bu kavramlara bir bütünlük içerisinde ulaşımın en kolay olacağ 1 şekilde dizayn edilmiş ve sanal ortama aktarılarak görsel materyal tamamlanmıştır.

Hazırlanan görsel materyal 540 bilimsel makale, 76 belgesel film ve 70 adet bilimsel veri hizmeti sunan internet sitesi incelenmiştir. Bu inceleme sonucunda 1173'ü .swf 24'ü ise .pdf uzantılı kavram elde edilmiştir. 


\section{Araştırmada Kullanılan Veriler}

Belgesel filmlerden elde edilen kavramlar, kitaplardan, internet web sitelerinden, bilim teknikteki kaynak makalelerden, ders notlarından ve Ferit Melen Kütüphanesi veri tabanından elde edilen önemli bilgiler ve bulgular incelenmiştir.

70 adet filmin içeriğine ait ve kavram kümesine uygun özet çıkartılmış ve filmlerin ayrıntılarına yönelik önemli sorular hazırlanmıştır. Her filmden kesilen kavramlardan oluşan kavram kümesi web sayfası (70 adet) hazırlanmıştır.

http://www.biyolojiegitim.yyu.edu.tr/f/kyctgdomtk.pdf

Her filmin kavram kümesine ait bir web sayfası ve bu web sayfasından her bir kavram filme linkle ulaşıla bilinecek şekilde hazırlanmıştır. Her kavramın araştırmadaki tanımı ve tanımının ait olduğu kavram filme link atılmıştır. Her kavrama ait web sayfasında; kavramın tanımı, kavram filmi, filmin süresi ve kavram kümesine link atılmıştır.

http://www.biyolojiegitim.yyu.edu.tr/kf/sgasteroit2/sgasteroit2.swf

Araştırma konusu ile ilgili kavramların alfabetik sıralama kuralına göre internet üzerinden yayınlanmış ve internet entegreli DVD hazırlanmıştır.

http://www.biyolojiegitim.yyu.edu.tr/kf/sg/sg.html

Araştırma konusu ile ilgili bilim teknik dergisinde yayınlanan 1968-2010 yılları arasında 540 adet makale gözden geçirilerek popüler fizik kavramları adı altında disipline edilerek internet web sayfaları hazırlanmıştır. Bu .pdf uzantılı 540 makale içerisinden 24 adet kavramın her birisine ana makalesine link atılmıştır.

http://www.biyolojiegitim.yyu.edu.tr/makale.html

Araştırmada 1173 adet .swf uzantılı kavramlara ilave olarak 24 adet .pdf uzantılı kavramla beraber 1197 adet kavram veri tabanı oluşturulmuştur.

\section{Sonuçlar}


Araştırmanın başlıca amacına uygun olarak popüler fizik kavramlarını ve kavram kümelerini içeren materyal hazırlanmıştır.

\section{http://www.biyolojiegitim.yyu.edu.tr/kf/sg/sg.html}

Hazırlanan materyalin görsel (film), işitsel (filmin sesi), tanımsal (filmin tanımı) ve zamansal (filmin süresi) açıdan, materyali kullanacak kişilere yararlı olabilmesi için materyalin örnek uygulaması Milli Eğitim Bakanlığına bağlı bir okulda yapılmış ve olumlu sonuçlar elde edilmiştir (Gülen ve Demirkuş, 2014a).

İnternetteki web sitelerinden, Yüzüncü Y1l Üniversitesi Ferit Melen Kütüphanesi toplu veri tabanından, bilim teknik dergisinden araştırma konusu ile ilgili filmlerden ve diğer medya ortamlarından edinilen bilgilere dayalı olarak araştırma konusu ile ilgili kavramların görsel-işitsel (kavram ve kavram kümesi filmi), yazımsal (kavram tanımı ve kavram filmi özeti), zamansal (filmin süresi) ve konumsal (kavram kümesi) tanımlarının bir arada veren benzer herhangi bir kaynağa rastlanmamıştır.

Hazırlanan materyalde belgesel kanallarında seyredilen bilimsel filmlerin içerdiği popüler fizik kavramları ile ilgili 1197 (1173 .swf ve 24 .pdf) tane kavram içeren bir sanal materyal (DVD) hazırlanmıştır. Popüler fizikte önemli kavramların internet üzerinden güncel olarak herkesin yararlanabileceği bir eğitim sitesinde hizmete sunulmuştur.

Hazırlanan materyalin, materyal geliştirme yöntemine yönelik yapılacak çalışmalara, ders materyali seçimine ve hazırlanmasına örnek teşkil edebileceği düşünülmektedir. Kavramlarla ilgili yapılan daha önceki benzer çalışmalara ilave olarak seçilen filmler ve resimler ya da diğer dokümanlar da kullanılarak; ilerde internete bütünleşik DVD şeklinde kavram ansiklopedisinin hazırlanmasına ön basamak oluşturulmuştur. 


\section{Öneriler}

Soyut ve ulaşılması zor olan kavramların öğretiminde sanal bilgisayar programlarının kullanımı ile sanal ders materyali hazırlanabileceği önerilmektedir.

Günlük hayatta her kesimden bireylerin karşılaştı̆̆ fakat bir anlam vermede veya şemalaştırmada zorlandığı soyut ve ulaşılması zor kavramların öğretim materyalinin (DVD) internet entegreli olarak hazırlanması popüler fizik kavramlarının öğrenilmesini kolaylaştıracağından kullanımı önerilmektedir.

Milli Eğitim Bakanlığı birimleri ile işbirliği içerisinde sanal- nesnel araçları kullanmayı ve materyal geliştirme seminer veya kurslarının yardımıyla materyal geliştirmenin kolaylaşacağı düşünülmektedir.

\section{Makalenin Bilimdeki Konumu (Yeri)}

İlköğretim Bölümü/ Fen Bilgisi Eğitimi Anabilim Dalı

\section{Makalenin Bilimdeki Özgünlüğü}

Soyut ve ulaşılması zor olan kavramların edinmesinde görsel materyalin önemi oldukça yüksektir. Bu önemle kavram eğitiminin verimli bir şekilde geçebilmesi için görsel, işitsel ve tanımsal sanal ders materyali hazırlanmıştır. Doküman incelenmesi ve analizi yöntemi ile hazırlanan bu materyal, materyal geliştirme ilkelerine bağlı kalınarak hazırlanmıştır. Bu materyal ile soyut ve ulaşılması zor olan kavramların eğitimi sağlanacaktır. Materyalin kullanılmaması durumunda öğrencilerin popüler fizik kavramları hakkında oluşturdukları zihinsel şemaların eksik veya yanlış olması kaçınılmazdır. Bu materyal erken çocukluk yaşından üniversite düzeyine kadar her kesim öğrencinin merak ettiği popüler fizik kavramlarının öğretilmesinde kullanılabilir. 


\section{Kaynakça}

Akalan, M.E. (2012). Bilgisayar destekli programlı ögretim yaklaşımına göre hazırlanmış ögretim teknolojileri ve materyal geliştirme dersinin öğrencilerin akademik başarısına etkisi ve ögrrenci görüşleri. Yayınlanmamış Yüksek Lisans Tezi, Gazi Üniversitesi Eğitim Bilimleri Enstitüsü, Ankara

Ata, A., \& Atik, A. (2016). Alternatif bir eğitim-öğretim ortamı olarak video paylaşım siteleri: Üniversitelerdeki youtube uygulamaları. Social Sciences,11(4), 312-325.

Aydemir Özyurt, E. (2016). Dördüncü sınıf Türkçe dersi öğretim programının görsel okuma ve sunu becerilerini geliştirme açısından incelenmesi. Yayınlanmamış Yüksek Lisans Tezi, Bartın Üniversitesi Eğitim Bilimleri Enstitüsü, Bartın.

Babacan, M. (2015). Nedir bu reklam? İstanbul: Beta Yayıncılık

Bayram, S. (2006). İlköğretimde materyal kullanımı. İstanbul: Morpa Kültür Yayınları.

Çakır, M., (2014). Görsel kültür ve küresel kitle kültürü. Ankara: Ütopya Yayınevi.

Çokluk, Ö., Yılmaz, K., \& Oğuz, E. (2011). Nitel bir görüşme yöntemi: Odak grup görüşmesi. Kuramsal Eğitimbilim, 4(1), 95-107.

Dalmış11, F., (2013). Müzik eğitiminde materyal geliştirme. Yayınlanmamış Yüksek Lisans Tezi, Pamukkale Üniversitesi Eğitim Bilimleri Enstitüsü, Denizli.

Demirkuş, N. (2017a). Biyolojide önemli kavramlar ders notlarl. Yüzüncü Y1l Üniversitesi. http://www.biyolojiegitim.yyu.edu.tr/ders/kav.htm Erișim tarihi 08.02.2016

Demirkuş, N., (2017b). Öğretim materyali geliştirme ders notları. http://biyolojiegitim.yyu.edu.tr/ders/otm.htm Erişim Tarihi: 08.02.2017 
Gülen, S. (2010). Popüler fizik kavramları içeren görsel ders materyali geliştirme çalışması. Yayınlanmamış Yüksek Lisans Tezi, Yüzüncü Yıl Üniversitesi Fen Bilimleri Enstitüsü. Van.

Gülen, S., \& Demirkuş, N., (2014a). Güneş sistemi ve ötesi: uzay bilmecesi ünitesinde, Görsel materyalin öğrenci başarısına etkisi. Yüzüncü Yıl Üniversitesi Eğitim Fakültesi Dergisi, 11(1), 1-19.

Gülen, S., \& Demirkuş, N. (2014b). Görsel materyalin öğrenci başarısına etkisi. Saarbrücken: Türkiye Alim Kitapları.

Gürbüz, R. (2006). Olasılık kavramıyla ilgili geliştirilen öğretim materyallerinin öğrencilerin kavramsal gelişimlerine etkisi. Buca Eğitim Fakültesi Dergisi, 20, 59-68.

Halls, J., (2012). Rapid video development for trainers: How to create learning videos fast and affordably. Virginia: American Society for Training \& Development.

Milli Eğitim Bakanlığı -MEB- (2013). İlköğretim kurumları (ilkokullar ve ortaokullar) fen bilimleri dersi (3,4,5,6,7 ve 8. Sinıflar) öğretim programı. Ankara: Talim ve Terbiye Kurulu Başkanlı̆̆ı.

Milli Eğitim Bakanlığı -MEB- (2017). İlköğretim kurumları (ilkokullar ve ortaokullar) fen bilimleri dersi (3,4,5,6,7 ve 8. Sinıflar) ögrretim programı. Ankara: Talim ve Terbiye Kurulu Başkanlığı (Taslak Program).

Özoğlu, H. H., \& Misıroğlu, Z. (2015). Ortaokul fen bilimleri 7 ders kitabı. Ankara: ADA matbaacılık ve Yayıncılık.

Öztaş, S.(2008). Tarih öğretimi ve filmler. Kastamonu Ĕ̆itim Dergisi, 16(2), 543-556.

Seels, B. Glasgow, Z. (1990). Exercises in instructional design. Colombus: Merrill Publishers. 
Seferoğlu, S. S. (2006). Öğretim teknolojileri ve materyal tasarımı. Ankara: Pegem Yayınc1lık.

Şahin, S. (2016). Eğitimde bilişim teknolojileri I-II. Ankara: Pegem Akademi.

Yelken, T. Y. (2009). Öğretmen adaylarının portfolyoları üzerinde grup olarak yaratıcılık temelli materyal geliştirmenin etkileri. Eğitim ve Bilim, 34(153), 83-98. 